\title{
Review
}

\section{Male circumcision: towards a World Health Organisation normative practice in resource limited settings}

\author{
Tim Hargreave $e^{1,2}$ \\ ${ }^{1}$ Senior Fellow, School of Clinical Science, Edinburgh University, Scotland, UK \\ ${ }^{2}$ Technical Adviser to the WHO, RHR -HRP Africa HIV Prevention Male Circumcision Programme
}

\begin{abstract}
There is now grade 1 evidence that male circumcision (MC) reduces the risk of a man acquiring HIV. Modelling studies indicate MC could in the next 10 years save up to 2 million lives in those African countries with high HIV prevalence. Several African countries are now scaling up public health MC programmes. The most effective immediate public health MC programmes in Africa will need to target 18-20 years old men. In the longer term there is a need for infant circumcision programmes. In order to implement more widespread MC there is a need to make the surgical procedures as simple as possible so that safe operations can be performed by paramedical staff. The WHO Manual of Male Circumcision under local anaesthetic was written with these objectives in mind. Included in the manual are three adult techniques and four paediatric procedures. The adult procedures are the dorsal slit, the forceps guided and the sleeve resection methods. Paediatric methods included are the plastibell technique, the Mogen and Gomco shield method and a standard surgical dorsal slit procedure. Each method is described in a step by step manner with photographic and line drawing illustrations. In addition to the WHO manual of surgical technique a teaching course has been developed and using this course it has been possible in one week to train a circumcision surgeon who has had no or minimal previous surgical experience. Further scaling will require training of circumcision surgeons, monitoring performance, training the trainer workshops as well as advocacy at national, international and government meetings. In addition to proceeding with standardised methods work is in progress to assess novel techniques in adults such as stay on ring devices and policies are being formulated as to how to assess new devices. Also work is in progress to explore efficiencies in surgical processing by task sharing. Proper informed consent and safety remain paramount and great care has to be taken as programmes in Africa scale up. In continental China where the HIV epidemic is at a much earlier stage there may be a case for considering infant circumcision but great care will be needed to ensure that there is no harm.
\end{abstract}

Asian Journal of Andrology (2010) 12: 628-638. doi: 10.1038/aja.2010.59; published online 19 July 2010.

Keywords: Africa, HIV, male circumcision

Correspondence to: Dr Tim Hargreave, 20 Cumin Place EH9 2JX, Edinburgh, Scotland, UK. A retired urological surgeon who is currently giving technical advice to the HRP Africa Male Circumcison programme. With Professor Dipo Otolarin he helped compile the first draft of the WHO MC Manual. He has also helped with the drafting of the Infant manual.

E-mail: tbhargreave@urologyedinburgh.co.uk

This paper is based on an invited presentation at the Third AsiaPacific Forum on Andrology, October 2009, Nanjing, China.

Received: 28 May 2010 Accepted: 15 June 2010

\section{Male Circumcision}

\subsection{Rationale for World Health Organisation Male} Circumcision programme

In the 1990s it was observed that there were marked regional variations in Africa in the prevalence of HIV $[1,2]$. At first this was thought to be because of the origin of the disease in West Africa and spread from that location by truck drivers [3] but as the epidemic developed it became clear that there was a coincidence 
between high prevalence of male circumcision (MC) and lower prevalence of HIV [4]. In fact this coincidence was so marked that some experts argued for immediate adoption of MC as an HIV preventative measure and there is to this day criticism of the failure to act on what some saw as overwhelming epidemiological evidence [5]. However, there was at that time and still today are a body of experts who oppose the promotion of MC, in part, because of doubts about epidemiologic evidence, particularly with respect to confounding factors such as sexual promiscuity and also because of doubts about the risk benefit ratio of any public health programme of MC particularly in the case of infant MC. Because there would always be doubts about observational evidence it was decided to undertake randomised trials of $\mathrm{MC}$ to test in a controlled fashion the impact of MC on HIV. Three large studies (Table 1) were undertaken in Africa (Orange Farm, South Africa [6-8]) and remarkably all three had to be stopped early as it was judged unethical to continue with the studies to planned conclusion number because the beneficial effect of the operation in terms of reduced HIV acquisition was so clear. The protective effect of MC seems to be sustained over time [9].

\subsection{What is the underlying biological mechanism of the protective effect of $M C$ ?}

It is important to know the biological mechanism whereby MC reduces the risk of HIV acquisition both because a plausible biological mechanism increases the credibility of epidemiological data and also because understanding the biology may open the door to additional preventative measures. The HIV virus gains entry by attaching to receptors on Langerhans cells [10-14]. Most HIV is killed within Langerhans cells but with each exposure there is a small chance that virus particles will overwhelm the killing mechanisms within Langerhans cells and then as part of normal second line defence the Langerhans cells will present antigen to circulating immune cells [10]. This is more likely to occur if there is exposure to high viral load [14]. Thus it is antigen presenting property of Langerhans cells that in some circumstance enables HIV to gain entry. Langerhans cells are found in the deeper layers of skin all over the body but are particularly dense and near to the surface on the mucosal aspects of the foreskin and penile shaft. MC removes many of the Langerhans cells. Those that are left are not so susceptible to taking up HIV, probably because the surface of the skin becomes dryer making it more difficult for HIV particles to attach; there is evidence about subprepucal moistness as a factor in a study of uncircumcised when it was found that the risk of HIV acquisition is greater in those men with longer foreskins and when the Mucosal surface is constantly moist [15]. Keratinisation may also protect and there is interest in whether keratinisation can be induced [16] but any change in keratinisation following MC is difficult to study because of the need for before and after biopsies and only in men who are having elective $\mathrm{MC}$ and without prior penile or foreskin pathology such as balanitis or phimosis. After MC, Langerhans cells are still present near to the surface in the remaining skin in the coronal area and therefore MC reduces but does not abolish risk. However, rather surprisingly there does not seem to be a difference in risk reduction in relation to how close the circumcision is to the corona; the forceps guided method (see below) usually leaves a 1-cm collar of skin that was formerly covered by the foreskin whereas the sleeve method leaves only one mm or two but both methods appear to be equally effective in terms of reduction of risk of acquisition

Table 1. Three male circumcision (MC) studies conducted in Africa [6-8].

\begin{tabular}{lccc}
\hline & Orange Farm (South Africa) & Rakai (Uganda) & Kisumu (Kenya) \\
\hline Population & Semi-urban & Rural & Urban \\
MC rate (\%) & 20 & 16 & 10 \\
HIV incidence (\%) & 1.6 & 1.3 & 1.8 \\
Age range (years) & $18-24$ & $15-49$ & $18-24$ \\
No. of men & 3128 & 5000 & 2784 \\
Interim analysis date when trial stopped & Nov. 2004 (April 2005) & Dec. 2006 (June 2007) & Dec. 2006 (Sept. 2007) \\
$\quad$ & & $22 / 43$ & $22 / 47$ \\
No. of infections in circ/uncirc group & $20 / 49$ & $48 \%$ & $53 \%$ \\
Protective effect of MC & $60 \%$ & & \\
\hline
\end{tabular}


of HIV indicating that factors such as moistness and keratinisation may be equally important to removing areas of Langerhans cells. Another potentially relevant factor maybe a difference if risk of sustaining penile trauma and open abrasions before and after MC, and in particular the risk of a torn fraenulum; it has recently been shown in the Kisumu project that bleeding and soreness are less frequent in man after circumcision compared with before [17].

\subsection{The known risks and Benefits of MC. Is a public health $M C$ programme justified?}

The benefits of MC extend beyond reduced chance of HIV acquisition and include improved personal hygiene (this may be particularly important in places with poor water supplies), it reduces risks of acquisition of HPV and penile warts and penile cancer [18], and reduces HSV2 and syphilis [19]. There is also evidence for reduced partner genital infections cancer, for example, reduced partner bacterial vaginosis $[20$, 21] HPV and reduced cervical cancer risk [6, 20-24]. MC however does not offer any protection against Neisseria gonorrhoeae, Chlamydia Trachomatis or Trichomomonas vaginalis [25]. However, for most of these conditions the numbers needed to treat are too large to justify MC as a public health measure, especially as unlike HIV there are for most of these conditions curative treatments available.

The risks of the operation of circumcision include damage from the surgery with a poor cosmetic result or actual damage to the penis [26], but in the context of proper training and continuing assessment of competence technical risks of the operation are low [27-28].

\subsection{Other possible risks of $M C$-Will MC change men's sexual behaviour?}

There is concern that men may regard MC as fully protective and that following MC male sexual responsibility will deteriorate (disinhibition) and that public health MC programmes could encourage sexual promiscuity and actually make HIV prevalence worse. To counteract this potentially harmful effect of $\mathrm{MC}$ most healthcare providers have followed $\mathrm{WHO}$ advice to deliver MC in the context of a male sexual health package with education about HIV and sexual responsibility and other HIV reduction measures such as condom provision and in information about the availability of HIV testing and counselling. It is particularly important that men understand that sexual activity is risky in all situations except the context of a faithful long term partner. So far the evidence is that men do not significantly alter sexual behaviour following circumcision [29-31], but there is a need for more and longer term data.

\subsection{Other possible risks of $M C$-Will MC decrease} male or female sexual pleasure?

There have also been concerns that both male and female sexual enjoyment is compromised by MC. This is a difficult area to study because in common with all studies of sensation it is difficult to make objective measurements and there are no good instruments to quantify sexual enjoyment in either partner and many studies are based on subjective responses to questions. The majority of studies (Table 2) in recent literature do not indicate any adverse effect on male sexual satisfaction. A consistent finding is a prolongation of ejaculatory latency time; this may be an advantage in younger men where quick ejaculation is very frequent. The effect of prolonged ejaculatory latency time has not been investigated in relation to circumcision status in older men.

Thus there is now good evidence for MC as part of the package of measures to try to reduce the spread of HIV and there is no evidence of significant or frequent harmful effects. These considerations underlie the WHO decision in 2007 [32] to advocate MC for HIV reduction and to develop a package of tools to help those African countries where the ministry of health wishes to implement country MC programmes. The WHO manual of technique [33] is one of the tools commissioned by HRP WHO in conjunction with UNAIDS and Jhpiego.

\section{WHO MC Manual}

\subsection{Production of the WHO MC Manual-timeline}

Work first started on a WHO manual of MC technique and the associated teaching materials in 2005 and before the results of the randomised trials were known so that in the likely event that the randomised trials concurred with the epidemiological evidence some materials would be available. The first step was a survey of world literature informed by the personal experience of one of the primary drafting authors and by a small steering committee and by visits to various centres including the University Hospital in Lusaka and the Jerusalem AIDS project. As it happens this decision 
Table 2. Some studies of male sexual satisfaction after male circumcision (MC).

\begin{tabular}{|c|c|}
\hline Reference & Comment \\
\hline Kigozi et al. 2008 male study [46] & Self reported sexual satisfaction after MC. \\
\hline Kigozi et al. 2009 female study [47] & $\begin{array}{l}\text { Self reported sexual satisfaction by women partners after their partners MC. } 2.9 \%(13 / 455) \\
\text { of women reported less sexual satisfaction; } 57.3 \%(255 / 455) \text { reported no change in sexual } \\
\text { satisfaction and } 39.8 \%(177 / 455) \text { reported an improvement in sexual satisfaction. }\end{array}$ \\
\hline Waldinger et al. 2009 [48] & $\begin{array}{l}\text { Five nations study of Intra Vaginal Ejaculatory Latency time as measured by a stopwatch. MC } \\
\text { made no difference. }\end{array}$ \\
\hline Cortés-González et al. 2008 [49] & No evidence of any deterioration in sexual satisfaction in 19 women following partners MC. \\
\hline Senol et al. 2008 [50] & $\begin{array}{l}\text { Measurement of Pudendal evoked responses before and after MC. Responses significantly } \\
\text { prolonged. Postulated this may benefit sexual enjoyment by prolonging time to ejaculation. }\end{array}$ \\
\hline Krieger et al. 2008 [51] & $\begin{array}{l}\text { Questions about sexual function to men participating in the Kisumu randomised trial. No } \\
\text { difference in sexual dysfunction between the groups. }\end{array}$ \\
\hline Aydur et al. 2007 [52] & No difference in sexual function/dysfunction depending on age of MC. \\
\hline Payne et al. 2007 [53] & $\begin{array}{l}\text { No difference in sensitivity between circumcised and non circumcised men during sexual } \\
\text { arousal. }\end{array}$ \\
\hline Kim and Pang 2007 [54] & $\begin{array}{l}\text { Modified Brief Medical Sexual Function Inventory score used with } 255 \text { circumcised men and } \\
118 \text { non circumcised. Decrease in masturbatory pleasure and sexual enjoyment after circumcision. }\end{array}$ \\
\hline Senkul et al. 2004 [55] & $\begin{array}{l}\text { No change in Brief Medical Sexual Function Inventory score in } 42 \text { men post MC. Increase in } \\
\text { ejaculatory latency time. }\end{array}$ \\
\hline Collins et al. 2002 [56] & $\begin{array}{l}\text { No change in Brief Medical Sexual Function Inventory score in } 15 \text { men post MC. Increase in } \\
\text { ejaculatory latency time. }\end{array}$ \\
\hline O’Hara and O'Hara 1999 [57] & $\begin{array}{l}\text { 20/138 women preferred intercourse after MC and } 118 / 138 \text { preferred intercourse before } \\
\text { their partner underwent MC. }\end{array}$ \\
\hline
\end{tabular}

Note: Excluded from this table are those studies where almost all the men had MC for treatment of penile pathology such as phimosis.

was correct and the WHO manual has been published in electronic format and has become established as one of the core tools in the Africa HIV MC programme. The first draft of the manual was available in the spring of 2006 and this was reviewed at an international consultation workshop held in Switzerland in 2006 attended by clinicians and stakeholders from Africa including clinicians involved in the three randomised trials. Following this consultation and revisions the manual was distributed more widely and revisions made according to comments received. The current version 3.5 was finalised in 2010 and is available in electronic form on the www.malecircumcision.org/.

\subsection{Developing the Africa MC programme: the need for an infant $M C$ manual}

The first priority has been operations for 18 year olds as this is an age before most young men acquire HIV, however, in the context of longer term country programmes $\mathrm{MC}$ is much easier if the operation is performed in infancy. Infant circumcision may be undertaken in the same facilities as adult MC but is more likely to be in the context of an obstetric service and in the case of normal full term delivery can be done soon after birth. For this reason it has been necessary to prepare a separate Infant MC manual and this is scheduled for publication in 2010 .

\subsection{Safety of $M C$}

$\mathrm{MC}$ is an intervention on a normal healthy man and therefore safety is paramount. Safety is important in terms of the risk benefit ratio for the individual man; most men are apprehensive about surgery on their penis! Therefore for men to accept MC the risks need to be very low in relation to the hoped for benefits of reduced HIV risk reduction especially when there are other measures a man could adopt such as universal condom use. Low risk is also very important in terms of advocacy for a country programme in that publicity about one bad complication can discredit the whole programme. In the description of each technique there is emphasis on training and safe technique with the intention of reducing any operative risk. In addition there are descriptions of how to manage complications 
and adverse events such as unexpected excess bleeding. In addition to learning MC technique the management of complications is built into the associated training materials.

\subsection{Layout of the Manual}

The manual is more than just a manual of technique but describes the package of interventions for an optimal MC programme. There are chapters on Education and Counselling and how to incorporate these components into a high throughput surgical programme. The surgical descriptions are done in a step by step fashion with each step illustrated by a photograph and line drawing. This has been done to facilitate copying and viewing the manual with the hope that the step by step illustrations will still be clear even if screen resolution or copying are less than optimal. The manual also includes information about the minimal clinic infrastructure and most importantly measures to prevent infection.

\subsection{Criteria for method inclusion in the WHO Male Circumcision Technique Manual}

The main criteria for method inclusion in the manual have been safety and evidence-based methods. However, this is difficult as many methods in common use have developed over many years often in the context of religious or cultural tradition and have become accepted but without detailed documentation of evidence such as procedure times, ease of learning and teaching or outcomes and costs. Fortunately there have been three large African studies and for one of them a new forceps guided method was devised [28]. This method has been included because outcome data is available and it has been shown to be practical in an African low resource context.

\subsubsection{Anaesthesia}

Adult men about to undergo circumcision do not need to debate the need for effective anaesthesia! In some European countries the use of general anaesthesia has been the normal practice, possibly because of patient embarrassment, but local anaesthesia is just as effective, safer and less costly [34]. When local anaesthesia is used there is no need for general anaesthesia recovery room facilities and this makes it practical to undertake $\mathrm{MC}$ in a clinic setting with a simpler procedure room and recovery area; considerations which are important in an African or low resource context. Therefore all the procedures described in the WHO manual can be safely undertaken with local anaesthetic.

There has been debate about whether there is a need for anaesthesia of any type for babies. There is overwhelming evidence in the literature that babies and infants feel pain and that anaesthesia should be used [35-38], and there is now general consensus that either topical (EMLA cream) or local anaesthetic injection [39], is needed. It may also help if the baby is allowed to suck during the procedure.

\subsubsection{Adult MC methods}

Three adult methods have been included in the manual. The dorsal slit method, the Sleeve resection method and the forceps guided method. The dorsal slit method is a generic method in wide use all over the world most often in the context of MC for foreskin pathology such as phimosis. The sleeve resection method is arguably the neatest technique and was used in the Rakai randomised trial and has the theoretical advantage that less mucosal skin is left behind compared with other methods, but has the theoretical disadvantage that more surgical skill may be needed compared with the other two methods. The forceps guided method was developed for the Kisumu randomised trial. The method has the advantage of surgical simplicity and maybe more suitable for use by those new to surgery but compared with the sleeve method leaves a larger cuff of sub coronal skin.

\subsubsection{Paediatric MC methods}

The paediatric methods described are the dorsal slit method, the Plastibell method, the Gomco clamp and the Mogen shield or clamp. There is a further distinction to be made between infant circumcision and preadolescent boys. The dorsal slit method would not normally be undertaken in infants except for gross foreskin pathology in a specialist unit but certainly not in the context of a public health HIV prevention infant MC programme. The other methods (Plastibell, Mogen clamp and Gomco clamp) are applicable for infants and are described in greater detail in a special WHO Infant MC manual (drafting completed, anticipated publication in 2010). The Mogen and Gomco clamps are surgical instruments which are best used for Infant circumcision. When used in Infants the foreskin is crushed and this produces haemostasis and the crushing also welds the cut edges so that sutures are generally not needed. Thus both devices are steps towards accurate and safe and speedy surgery. The plastibell is 
a stay on disposable device which is tightly tied on the foreskin and becomes detached and falls off naturally leaving a neat result. Again the method is quick and achieves haemostasis. There is great interest in these device related methods for older children and adults (see below). In infants the penis is small with a relatively undeveloped blood supply and post operative penile erections are not a significant factor and these may be reasons why there has been widespread use of all these devices in infant circumcision in various countries but their use in adults remains experimental.

\section{Training and continuing professional development of circumcision surgeons}

When selecting potential trainees to learn MC surgery and procedures there are two considerations. Firstly the regulatory and legal framework in the country where a MC programme is planned and secondly what sort of person is capable of performing a safe surgical procedure. In some countries there is a legal requirement that any surgical procedure must be undertaken by a qualified doctor; this poses particular problems in the scale up of MC services because more often than not there are not enough doctors and many of the doctors who are in the country are engaged in private medical practice. For this reason MC programmes in some countries may need to incorporate the private medical sector. From a purely technical point of view there are many examples of non-medically qualified surgical assistants undertaking quite complex surgical procedures, for example theatre assistants in the USA who close operation incisions after the principle surgeon has left, surgical assistants undertaking repair of vesicovaginal fistula in some African countries etc. There is no reason for a requirement for a medical qualification for safe MC provided there is good training and continuing monitoring to ensure maintenance of competency. In most African countries there is a strong case for training non-medically qualified male vircumcision surgeons because of the need for large numbers of circumcision operations and to prevent asset striping of existing medical services and ultimately this may strengthen a country medical service. The minimum entry requirements for training include an education level sufficient to understand the training materials (this will be the equivalent of completion of secondary education) and manual dexterity. The level of education is determined by school leaving qualifications or university qualification but so far there is no formal method to assess manual dexterity. Traditional surgical training in western countries is based on several years of apprenticeship with mentoring by senior surgeons and those who lack sufficient dexterity are directed into alternative branches of medicine. For many African Male Circumcision Programmes there is a need to scale up quickly and for training to be compressed into a short time frame. One suggestion that has been made is to teach a class of new recruits a simple techniques such as suturing and then to give the class a timed task such as placing 10 sutures in a foam block and to eliminate from further training the bottom quartile in terms of performance of the task with judgment being made both on completion of the task and the accuracy and neatness of the job. So far, however, such assessments are not routine, and the elimination of unsuitable trainees is an informal process which relies on the judgement of training workshop leaders.

\subsection{How to train}

Much traditional surgical training depends on a long apprenticeship system but this is not practical in the context of rapid scale up of MC programmes in Africa. For this reason training materials suitable for training workshops have been developed by jhpeigo in parallel with the WHO MC Manual. The training workshop has been predicated on a one week training period. The training materials were piloted in a workshop in Lusaka in May 2007. At that workshop there were 10 trainees and it was possible in one week to train someone with no previous surgical experience to a degree of competency to safely perform MC surgery on an adult male. The training programme comprised a series of lectures to give information about the rationale for $\mathrm{MC}$ and also a detailed description of the technique to be learned. The practical aspects comprised surgical exercises such as suturing knot tying holding instruments but also more general operation procedure room techniques such as hand washing and sterile technique. Also there was observation of live procedures undertaken by the trainer and then assistance and finally undertaking MC procedures assisted by the trainer. The whole course was run in workshop style at the Lusaka University Teaching Hospital using a dedicated teaching facility as well as the hospital operating rooms. Although the WHO manual describes a number of $\mathrm{MC}$ techniques it is envisaged that within a 
country or area only one technique will be adopted and therefore in the training workshop the hands on training is only given in one technique. A number of training workshops have now been held in Kenya and Zambia. In Kenya 650 providers had been trained in Nyanza province by September 2009 and approximately 150 in Zambia.

\subsection{Achieving competence}

It has been shown possible to train someone with no surgical experience to a degree of competency in a one week course but following such a course there is a need for continued supervision until full competency is achieved. The level of supervision needed will depend on the complexity of the MC method previous surgical experience of the trainee but assuming no prior experience then the best model involves teams of circumcision surgeons so that the new trainees can work with an experienced provider for several months before progressing to become a team leader or even trainer. Evidence for Rakia indicates that the circumcision surgeon needs to perform approximately 100 sleeve procedures to attain competence [40].

\subsection{Maintaining competence}

MC programmes will be delivered by a variety of providers both in the public and private sector and by different NGOs and agencies. It is important that safe techniques are used and that governments insist on proper training and continuing supervision. Ideally this should include the surgeon keeping a logbook of procedures undertaken and clinics should maintain a record of adverse events and complications. The clinic culture should encourage blame free recording of adverse event and problem solving to reduce problems in the future. These ideals are much more easily obtained with team working and task sharing as everyone in the team shares responsibility. Accurate record keeping is a vital component of maintaining competence, particularly recording instances of infection.

\subsection{Simplified instrument kits}

Worldwide most adult MC operations are performed in an operating theatre or a procedure room which is equipped to undertake a variety of surgical procedures and in this context a variety of surgical instruments are usually packed in trays suitable for various minor procedures (minor procedure tray). However, in the context of a service providing large numbers of infant or adult MC procedures there is a need for dedicated
$\mathrm{MC}$ instrument kits comprising the minimum number of items and including all items needed such as antiseptic solution sachet, local anaesthesia agent and a disposable surgical drape. There are several advantages to kits as these can be packed and sterilised centrally. There is also the possibility of totally disposable kits but the issue of disposable versus non-disposable needs careful consideration. In general Haemostatic artery forceps made from plastic are not satisfactory compared with ones made from metal once because the plastic is too soft and the jaws are too large for accurate surgery. However, if may be possible to manufacture disposable metal or plastic instruments that are of sufficient quality. This however brings about another problem. Many hospitals in Africa have poor and worn surgical instruments and when disposable instrument quality is good there is an overwhelming temptation to reuse these instruments as they seem better than those the hospital has. The problem is that disposable instrument are not designed to tolerate he sterilisation procedures and either cannot be properly sterilised or the material degrades and becomes unsafe.

There is a good case for prepacked kits with sufficient but no excess instruments but with standard quality surgical instrument that can be re-sterilised. The use of disposable instrument may be possible but only if there is a sure policy of safe disposal of used instruments.

There is great interest in development of adult circumcision devices (see below) and clearly these can be packed in disposal kits. A design consideration for the device itself is that it should ideally autodestruct after use and or be impossible to reuse.

\subsection{Minimum clinic standards}

The WHO manual has been written to that operations can be safely undertaken in a proper procedure room with aseptic precautions and there is no need for full operating theatre or general anaesthesia facilities. There is a need for hand washing and disinfection and this requires a clean water supply and this can be a problem in those places with poor water supply. All the procedures described in the manual can be undertaken without diathermy and therefore although adequate lighting is needed this can be provided by battery in places with an uncertain electricity supply. The procedure room should be constructed with materials that can be wiped clean and if diathermy is to be used then the procedure table and floor need to comply with 
electrical insulation standards as recommended by the diathermy machine manufacturers. It is envisaged that many $\mathrm{MC}$ procedures in Africa will be undertaken in clinic facilities which are not necessarily in a hospital.

\section{Other issues related to $\mathrm{MC}$}

\subsection{MC move project-task sharing}

There is a need to explore way to undertake large number of MC procedures in as short a time as possible and with limited numbers of providers. For this reason there has been consideration of task sharing. The benefit of task sharing is well demonstrated in the Aravind Eye project in India where more than 300000 eye operations have been performed made possible by task sharing with trained assistants undertaking all preoperative and postoperative care and leaving the surgeon to concentrate on the surgical procedure. Task sharing for $\mathrm{MC}$ has been undertaken in the Orange Farm clinic in South Africa. MC can be divided into a number of steps such as preoperative preparation, giving anaesthesia, undertaking the procedure, applying the dressing and postoperative care and discharge instructions. Various models can be considered, for example with trained providers specialising in one of the above steps or alternatively with trained providers able to undertake all of the above steps and with rotation of duties. There is a need to evaluate these different models in terms of providing sustainable service.

\subsection{Introducing new MC methods and devices}

There is a need for new methods that are equally safe compared with current standard methods but which can be done with less resource or with less skill or more speedily or all three. The major interest centres on clamps and devices. The requirements for any device seem to be different between adults and prepubertal children and babies. This is probably to do with the degree of penile development and frequency of penile erections which dictate different mechanical requirements for any device. Thus any contender dev ice has to be separately evaluated in these three target groups.

In 2009 a WHO consultation was held to discuss the requirement for the evaluation of a new device (draft report of meeting completed publication in progress). Briefly the device should first satisfy normal regularity requirement with respect to materials and contact with tissue. The contender device should then be pilot tested in a small group of 5-6 men and the results should be carefully evaluated. If possible each case should be documented with photographs so that these can be reviewed later. Provided this initial pilot is safe then the number of participants should be increased to approximately 25 and another review should take place. If all is well then the number should be increased to 100 . If the device satisfies this initial safety and practicality testing then further studies need to be undertaken to compare the device with one of the standard methods with consideration of safety and efficacy and costs ease of use practicality in resource limited settings etc.

The current interest in devices centres on the use of adult male stay on disposable devices such as the Shang Ring $[41,42]$. There seems to be great potential for the use of these devices in the context of undertaking many thousands of procedures. However, the lure of financial reward for selling thousands of devices must not be allowed to obscure the need for rigorous appraisal of trial results and for this reason investigators should arrange for trial results to be evaluated by experts who are independent of the trial and not in any way connected with the company that makes the device. At the time of writing this article the results of studies of the Shang ring look very promising [41], however, there is conflicting data on the Tara Klamp [42]. There are other devices such as the Cric Prepex which look promising and the sophisticated acucirc; this later is however currently too expensive in the context of most African MC programmes.

\subsection{Unanswered questions}

There remain many concerns and unanswered questions. So far evidence suggests no major change in men's sexual behaviour following adult circumcision but there is a need for more data and long term follow up. There is also a need for information about whether MC affects women's ability to negotiate condom use. There are anecdotal reports that circumcised men find condoms easier to use and there is a need for further information about this and also whether condom use is influenced by the education component that is built into current African MC programmes. There is a need to understand wound healing following circumcision in relation to HIV acquisition risk and how long men should be advised to abstain from sexual activity and use condoms to protect the wound. Currently men are advised to use condoms to protect the wound; this 
advice was based on common sense precautionary principles but needs to be assessed scientifically. It is possible that some men who have never previously used condoms may be encouraged to do so. There is a continuing need to improve safety and efficacy of the circumcision procedure. This may involves improved procedures and practices such as task sharing and the safe use of diathermy but also innovations such as tissue glues [43, 44] haemostatic gauze, antibiotic prophylaxis, ultrasonic scalpel [45]. Finally there is great potential for device suitable for use in adults as the use of devices could potentially enable a centre to safely perform hundreds rather than tens of procedures during a day. However enthusiasm has to be tempered with objectivity and safety must remain paramount.

\subsection{Ethical considerations and infant circumcision}

There remains a major ethical concern because infants cannot give consent and some argue that the risks exceed the benefits. However, parents have always given consent for public health measure that will benefit their children such as the many different childhood vaccinations. This consent is given despite the risks involved because of overwhelming benefit. Infant circumcsion has been the normal cultural practice for many hundreds of years in Islamic and Jewish cultures and there is no evidence of any harm and indeed there is some evidence of some other benefit in terms of reduced risk of other sexually transmitted infections (see above). Analylis of the risk benefit ration for infant circumcision in those countries with high HIV prevalence is in favour of the procedure. Some authorities argue that $\mathrm{MC}$ should be more widely advocated as a public health measure in all countires but this remains controversial. There is a special case to consider in counties with current relatively low HIV prevalence and where the majoirty of men are uncircumcised in terms of preventing increased HIV prevalence in the future. In this situation the individual benefit is low but the benefit to the future population may be high as demonstrated by those Islamic Afrcian countires where MC is noraml cultural practice compared with non islamic africa countires with low MC rates and high HIV prevlance.

\subsection{Progress to date}

In October 2009 appoximately 40000 thousand adult MC have been done in Kenya and 4000 in Zambia and in addtiion to scaling up attention is now turning to sutainable MC programmes based on infant circumcision. Infant circumcision programmes will not produce benefit in terms of HIV reductionn for 20 years or more and the rationale for infant programmes can be question because it is possible that other HIV preventative measure will become available such as vaccines microbicidal gels etc. However, the prospect of HIV vaccines has been a tantalising and disppointing goal for 20 years and there is no certaintity that they will become a reality in the next 20 years; other measures such as precoital microbicides or prophylactic anteretrovirals are unlikely to become truely effective population preventative measures and therefore it seems risky not to embark on infant programmes.

\section{Abbreviations}

HRP Human Reproduction Programme (UNDP, UNFPA, WHO, World Bank Special Programme of Research, Development and Research Training in Human Reproduction is the main instrument within the United Nations systerm for research in Human Reproduction. HRP is housed within the WHO complex. The main responsibility for HIV related work is with UNAIDS (see below) but some research and programme implementation work is undertaken by HRP in collaboration with UNAIDS.

UNAIDS is the Joint United Nations Programme on HIV/AIDS and is a distinct UN Agency housed in a seperate building across from the main WHO building. It has a current mission statement of the new vision is "Zero new HIV infections. Zero discrimination. Zero AIDSrelated deaths." http://www.unaids.org/en/default.asp.

Jhpiego is not an acronym and is an international non-profit health organization affiliated with Johns Hopkins University, http://www.jhpiego.jhu.edu.

MC Male Circumcision is the term for the operation to remove the foreskin of the penis. Formerly the term circumcision was used but the term Male Circumcision has now been adoped by WHO to distinguish the procedure from Female Genital Mutilation (FGM) which has sometimes been known as Female Circumcision. This is important because whereas MC has health benefits FGM is wholly harmful.

\section{References}

1 Fink AJ. A possible explanation for heterosexual male infection with AIDS. N Engl J Med 1986; 315: 1167.

2 Moses S, Bradley JE, Nagelkerke NJ, Ronald AR, Ndinya- 
Achola JO, et al. Geographical patterns of male circumcision practices in Africa: association with HIV seroprevalence. Int J Epidemiol 1990; 19: 693-7.

3 Lavreys L, Rakwar JP, Thompson ML, Kackson DJ, Mandaliya $\mathrm{K}$, et al. Effect of circumcision on incidence of human immunodeficiency virus type 1 and other sexually transmitted diseases: a prospective cohort study of trucking company employees in Kenya. J Inf Dis 1999; 180: 330-6.

4 Weiss HA, Quigley MA, Hayes RJ. Male circumcision and risk of HIV infection in sub-Saharan Africa: a systematic review and meta-analysis. AIDS 2000; 14: 2361-70.

5 Renton A. Failure to circumcise men 'may have cost millions of AIDS deaths'. The Observer, 2009; http:/www.guardian. co.uk/world/2009/jul/05/hiv-circumcision-africa-who-un.

6 Auvert B, Sobngwi-Tambekou J, Cutler E, Nieuwoudt M, Lissouba $\mathrm{P}$, et al. Effect of male circumcision on the prevalence of high-risk human papillomavirus in young men: results of a randomized controlled trial conducted in orange farm, South Africa. J Infect Dis 2009; 199: 14-19.

7 Bailey RC, Moses S, Parker CB, Agot K, Maclean I, et al. Male circumcision for HIV prevention in young men in Kisumu, Kenya: a randomised controlled trial. The Lancet 2007; 369: 643-56.

8 Gray RH, Kigozi G, Serwadda D, Makumbi F, Watya S, et al. Male circumcision for HIV prevention in men in Rakai, Uganda: a randomised trial. Lancet 2007a; 369: 657-66.

9 Bailey RC, Moses S, Parker CB. The protective effect of male circumcision is sustained for at least 42 months: results from the Kisumu, Kenya trial. XVII International AIDS Conference, Mexico City, August 3-8, 2008. (Abstract only)

10 de Witte L, Nabatov A, Pion M, Fluitsma D, de Jong MA, et al. Langerin is a natural barrier to HIV-1 transmission by Langerhans cells. Nat Med 2007; 13: 367-71.

11 Donoval BA, Landay AL, Moses S, Agot K, Ndinya-Achola $\mathrm{JO}$, et al. HIV-1 target cells in foreskins of African men with varying histories of sexually transmitted infections. Am J Clin Pathol 2006; 125: 386-91.

12 Short RV. New ways of preventing HIV infection: thinking simply, simply thinking. Philos Trans R Soc Lond B Biol Sci 2006; 361: 811-20.

13 Weiss G, Westbrook R, Sanders M. The distribution and density of Langerhans cells in the human prepuce: site of a diminished immune response. Isr J Med Sci 1993; 29: 42-3.

14 Quinn TC, Wawer MJ, Sewankambo N, Serwadda D, Li C, et al. Viral load and heterosexual transmission of human immunodeficiency virus type 1. N Engl J Med 2000; 342: 921-9.

15 O'Farrell N, Morison L, Moodley P, Pillay K, Vanmali T, et al. Association between HIV and subpreputial penile wetness in uncircumcised men in South Africa. J Acquir Immune Defic Syndr 2006; 43: 69-77.

16 Laurence J. Keratinization: a biologic alternative to male circumcision in the prevention of HIV infection? AIDS Read 2008; 18: 394-5.

17 Mehta SD, Krieger JN, Agot K, Moses S, Ndinya-Achola $\mathrm{JO}$, et al. Circumcision and reduced risk of self-reported penile coital injuries: results from a randomized controlled trial in kisumu, kenya. J Urol 2010. [Epub ahead of print]

18 Daling JR, Madeleine MM, Johnson LG, Schwartz SM, Shera KA, et al. Penile cancer: importance of circumcision, human papillomavirus and smoking in in situ and invasive disease. Int J Cancer 2005; 116: 606-16.

19 Tobian AA, Serwadda D, Quinn TC, Kigozi G, Gravitt PE, et al. Male circumcision for the prevention of HSV-2 and HPV infections and syphilis. N Engl J Med 2009; 360: 1298-309.

20 Fethers KA, Fairley CK, Hocking JS, Gurrin LC, Bradshaw CS. Sexual risk factors and bacterial vaginosis: a systematic review and meta-analysis. Clin Infect Dis 2008; 47: 1426-35.

21 Gray RH, Kigozi G, Serwadda D, Makumbi F, Nalugoda F, et al. The effects of male circumcision on female partners' genital tract symptoms and vaginal infections in a randomized trial in Rakai, Uganda. Am J Obstet Gynecol 2009; 200: 42. e1-e7.

22 Auvert B, Lissouba P, Cutler E, Zarca K, Puren A, et al. Association of oncogenic and nononcogenic human papillomavirus with HIV incidence. J Acquir Immune Defic Syndr 2010; 53: 111-6.

23 Bosch FX, Albero G, Castellsagu X. Male circumcision, human papillomavirus and cervical cancer: from evidence to intervention. J Fam Plann Reprod Health Care 2009; 35: 5-7.

24 Castellsague X, Bosch FX, Muñoz N, Meijer CJ, Shah KV, et al. Male circumcision, penile human papillomavirus infection, and cervical cancer in female partners. N Engl J Med 2002; 346: 1105-12.

25 Mehta SD, Moses S, Agot K, Parker C, Ndinya-Achola JO, et al. Adult male circumcision does not reduce the risk of incident Neisseria gonorrhoeae, Chlamydia trachomatis, or Trichomonas vaginalis Infection: Results from a randomized, controlled trial in Kenya. J Infect Dis 2009; 200: 370-8.

26 Ozkan S, Gurpinar T. A serious circumcision complication: Penile shaft amputation and a new reattachment technique with a successful outcome. J Urol 1997; 158: 1946-7.

27 Ben Chaim J, Livne PM, Binyamini J, Hardak B, Ben-Meir $\mathrm{D}$, et al. Complications of circumcision in Israel: a one year multicenter survey. Isr Med Assoc J 2005; 7: 368-70.

28 Krieger JN, Bailey RC, Opeya J, Ayieko B, Opiyo F, et al. Adult male circumcision: results of a standardized procedure in Kisumu District, Kenya. BJU Int 2005; 96: 1109-13.

29 Agot KE, Kiarie JN, Nguyen HQ, Odhiambo JO, Onyango $\mathrm{TM}$, et al. Male circumcision in Siaya and Bondo Districts, Kenya: prospective cohort study to assess behavioral disinhibition following circumcision. J Acquir Immune Defic Syndr 2007; 44: 66-70.

30 Mattson CL, Campbell RT, Bailey RC, Agot K, NdinyaAchola $\mathrm{JO}$, et al. Risk compensation is not associated with male circumcision in Kisumu, Kenya: a multi-faceted assessment of men enrolled in a randomized controlled trial. PLoS One 2008; 3: e2443.

31 Bailey RC, Neema S, Othieno R. Sexual behaviors and other HIV risk factors in circumcised and uncircumcised men in Uganda. J Acquir Immune Defic Syndr 1999; 22: 294-301.

32 WHO and UNAIDS announce recommendations from expert 
consultation on male circumcision for HIV prevention. 2007: http://www.who.int/hiv/pub/malecircumcision/research_implications/en/index.html.

$33 \mathrm{WHO} / \mathrm{UNAIDS} / \mathrm{HPIEGO}$. Manual for male circumciison under local anaesthesia. World Health Organisation. 2006: http://www.malecircumcision.org/training/documents/MC manual_local_anaesthesia.pdf.

34 Goulding FJ. Penile block for postoperative pain relief in penile surgery. J Urol 1981; 126: 337.

35 Butler-O'Hara M, LeMoine C, Guillet R. Analgesia for neonatal circumcision: A randomized controlled trial of EMLA cream versus dorsal penile nerve block. Pediatrics 1998; 101: E5. http://www.pediatrics.org/cgi/content/full/101/4/e5.

36 Hardwick-Smith S, Mastrobattista JM, Wallace PA. Ring block for neonatal circumcision. Obstet Gynecol 1998; 91: 930-4.

37 Kurtis PS, DeSilva HN, Bernstein BA, Malakh L, Schrechter NL. A comparison of the Mogen and Gomco clamps in combination with dorsal penile nerve block in minimizing the pain of neonatal circumcision. Pediatrics 1999; 103: E23.

38 Lander J, Brady-Fryer B, Metcalfe JB, Nazarali S, Muttitt S. Comparison of ring block, dorsal penile nerve block, and topical anesthesia for neonatal circumcision. A randomized controlled trial. J Am Med Assoc 1997; 278: 2157-62.

39 Kirya C, Werthmann M. Neonatal circumcision and penile dorsal nerve block: a painless procedure. J Pediatr 1978; 92: 998-1000.

40 Kiggundu V, Watya S, Kigozi G, Serwadda D, Nalugoda F, et al. The number of procedures required to achieve optimal competency with male circumcision: findings from a randomized trial in Rakai, Uganda. BJU Int 2009; 104: 529-32.

41 Cheng Y, Peng YF, Liu YD, Tian L, L NQ, et al. A recommendable standard protocol of adult male circumcision with the Chinese Shang Ring: outcomes of 328 cases in China] [Article in Chinese. Zhonghua Nan Ke Xue 2009; 15: 584-92.

42 Lagarde E, Taljaard D, Puren A, Auvert B. High rate of adverse events following circumcision of young male adults with the Tara KLamp technique: a randomised trial in South Africa. S Afr Med J 2009; 99: 163-9.

43 Subramaniam R, Jacobsen AS. Sutureless circumcision: a prospective randomised controlled study. Pediatr Surg Int 2004; 20: 783-5.

44 Elmore JM, Smith EA, Kirsch AJ. Sutureless circumcision using 2-octyl cyanoacrylate (Dermabond): appraisal after 18-month experience. Urology 2007; 70: 803-6.

45 Fette A, Schleaf J, Haberlik A, Seebacher U. Circumcision in paediatric surgery using an ultasound dissection scalpel. Technol Hlth Care 2000; 8: 75-9.

46 Kigozi G, Watya S, Polis CB, Buwembo D, Kiggundu V, et al. The effect of male circumcision on sexual satisfaction and function, results from a randomized trial of male circumcision for human immunodeficiency virus prevention, Rakai, Uganda. BJU Int 2008; 101: 65-70.

47 Kigozi G, Lukabwe I, Kagaayi J, Wawer MJ, Nantume B, et al. Sexual satisfaction of women partners of circumcised men in a randomized trial of male circumcision in Rakai, Uganda. BJU Int 2009; 104: 1698-701.

48 Waldinger MD, McIntosh J, Schweitzer DH. A five-nation survey to assess the distribution of the intravaginal ejaculatory latency time among the general male population. J Sex Med 2009; 6: 2888-95.

49 Cortés-González JR, Arratia-Maqueo JA, Gómez-Guerra LS. Does circumcision has an effect on female's perception of sexual satisfaction? [Article in Spanish]. Rev Invest Clin 2008; 60: 227-30.

50 Senol MG, Sen B, Karademir K, Sen H, Saraçoðlu M. The effect of male circumcision on pudendal evoked potentials and sexual satisfaction. Acta Neurol Belg 2008; 108: 90-3.

51 Krieger JN, Mehta SD, Bailey RC, Agot K, Ndinya-Achola JO, et al. Adult male circumcision: Effects on sexual function and sexual satisfaction in Kisumu, Kenya. J Sex Med 2008; 5: 2610-22.

52 Aydur E, Gungor S, Ceyhan ST, Taiimaz L, Baser I. Effects of childhood circumcision age on adult male sexual functions. Int J Impot Res 2007; 19: 424-31.

53 Payne K, Thaler L, Kukkonen T, Carrier S, Binik Y. Sensation and sexual arousal in circumcised and uncircumcised men. J Sex Med 2007; 4: 667-74.

54 Kim D, Pang MG. The effect of male circumcision on sexuality. BJU Int 2007; 99: 1169-70.

55 Senkul T, Iseri C, Sen B, Karademir K, Saracoglu F, et al. Circumcision in adults: Effect on sexual function. Urology 2004; 63: 155-8.

56 Collins S, Upshaw J, Rutchik S, Ohannessian C, Ortenberg J, et al. Effects of circumcision on male sexual function: Debunking a myth? J Urol 2002; 167: 2111-2.

57 O'Hara K, O'Hara J. The effect of male circumcision on the sexual enjoyment of the female. BJU Int 1999; 83 (suppl 1): 93-102. 